Georgia State University

ScholarWorks @ Georgia State University

8-13-2019

\title{
Effect of Sex and Dyad Composition on Speech and Gesture Development of Singleton and Twin Children
}

hatice sumeyra ozturk

georgia state university

Follow this and additional works at: https://scholarworks.gsu.edu/psych_theses

\section{Recommended Citation}

ozturk, hatice sumeyra, "Effect of Sex and Dyad Composition on Speech and Gesture Development of Singleton and Twin Children." Thesis, Georgia State University, 2019.

doi: https://doi.org/10.57709/14860709

This Thesis is brought to you for free and open access by the Department of Psychology at ScholarWorks @ Georgia State University. It has been accepted for inclusion in Psychology Theses by an authorized administrator of ScholarWorks @ Georgia State University. For more information, please contact scholarworks@gsu.edu. 


\title{
EFFECT OF SEX AND DYAD COMPOSITION ON SPEECH AND GESTURE DEVELOPMENT OF SINGLETON AND TWIN CHILDREN
}

by

\section{H. SÜMEYRA ÖZTÜRK}

Under the Direction of Şeyda Özçalişkan, PhD

\begin{abstract}
Children show sex differences in early vocabulary development—with boys having smaller vocabularies than age-comparable girls - a pattern that becomes evident in both singleton and twin dyads. Twins also use fewer words than their singleton peers. However, we know relatively less about sex differences in early gesturing in singletons and twins, except for a few studies suggesting a female advantage in gesturing among singletons. We examine the patterns of speech and gesture production of 1;6-to 2;0-year-old singletons and twins in structured play interactions with their parents. Boys and girls were comparable in their speech and gesture production, but singletons used greater amount and diversity of speech and gestures than twins. There was, however, no effect of twin dyad type on either speech or gesture production. These results further confirm the close integration between gesture and speech at the early stages of language development in twins.
\end{abstract}

INDEX WORDS: Twin language, Twin gesture, Sex Differences, Language Development, Early Gestures, Early language 


\section{EFFECT OF SEX AND DYAD COMPOSITION ON SPEECH AND GESTURE DEVELOPMENT OF SINGLETON AND TWIN CHILDREN}

By

\section{H. SÜMEYRA ÖZTÜRK}

A Thesis Submitted in Partial Fulfillment of the Requirements for the Degree of Master of Arts

in the College of Arts and Sciences

Georgia State University 
Copyright by

H. Sümeyra Öztürk

2019 


\section{EFFECT OF SEX AND DYAD COMPOSITION ON SPEECH AND GESTURE DEVELOPMENT OF SINGLETON AND TWIN CHILDREN}

By

H. SÜMEYRA ÖZTÜRK

Committee Chair: Şeyda Özçalışkan

Committee: Rose Sevcik

Nihan Ketrez

Electronic version approved:

Office of Graduate Studies

College of Arts and Sciences

Georgia State University

August 2019 


\section{DEDICATION}

I dedicate this study to my parents who always believed in me. I also dedicate this to my sisters who always supported me during hard times. 


\section{ACKNOWLEDGEMENTS}

First, I would like to express my sincere gratitude to my advisor and committee chair, Dr. Şeyda Özçalışkan, for her support, immense knowledge and motivation, and my committee members Dr. Rose Sevcik and Dr. Nihan Ketrez for their invaluable feedback and guidance. I also thank Dr. Nihan Ketrez for the collection of the data and to all the children who participated in this project. I also thank my research assistants Melis Çiftçi and Fatih Şahinkayası for their diligent work in data transcription and coding. Lastly, thanks to the members of the Gesture and Language Lab_-Ebru Pınar, Valery Limia, Kübra Şengül, Murat Şengül and Stephanie Baumann for their feedback and support. 


\section{TABLE OF CONTENTS}

ACKNOWLEDGEMENTS V

LIST OF TABLES

VIII

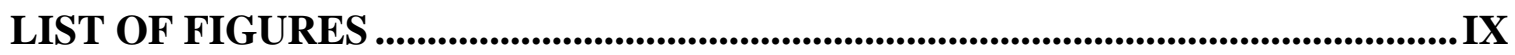

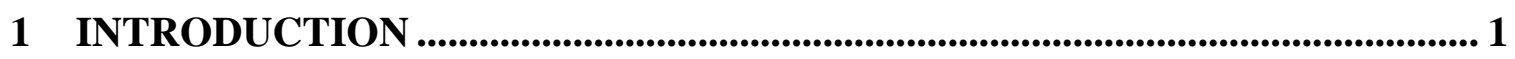

1.1 Sex differences in early speech and gestures produced by singletons ............ 1

1.2 Sex differences in early speech and gestures produced by twins.................... 3

1.3 Differences between singletons and twins in early speech and gesture.......... 5

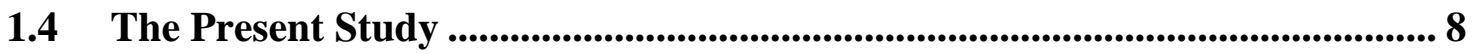

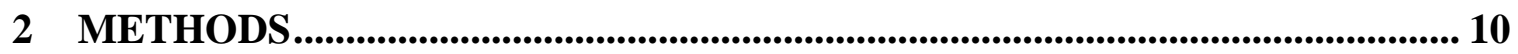

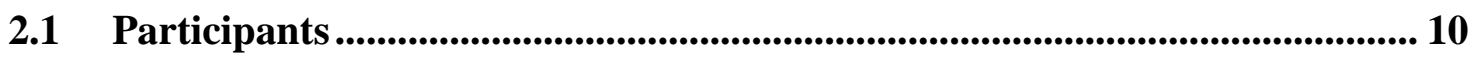

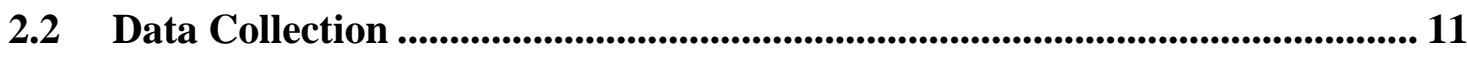

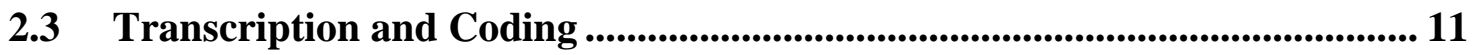

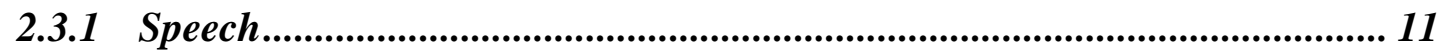

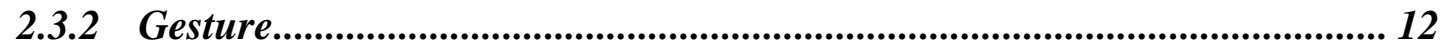

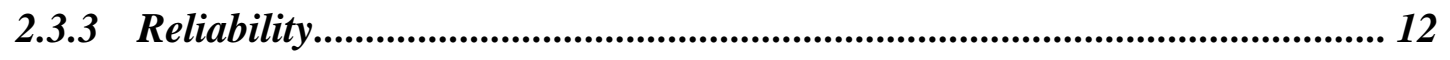

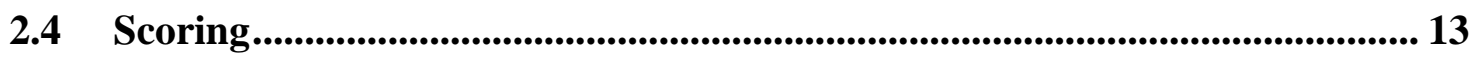

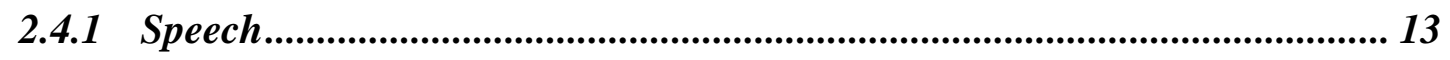

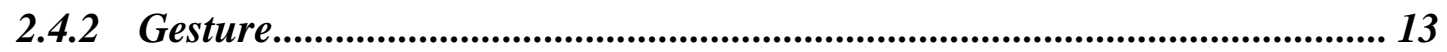

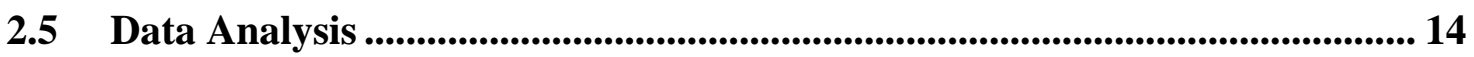




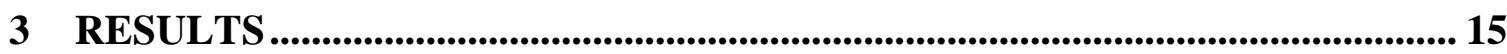

3.1 Do children show sex or group differences in the amount, diversity, and complexity of speech and gestures that they produce?

3.2 Do twin children show dyad composition differences in the amount, diversity, and complexity of speech and gestures that they produce? .............................. 18

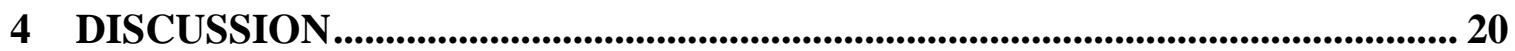

4.1 Group differences in gesture and speech of singletons and twins ............... 20

4.2 Sex differences in gesture and speech........................................................... 22

4.3 Differences in the complexity of the gestures children produced ................. 23

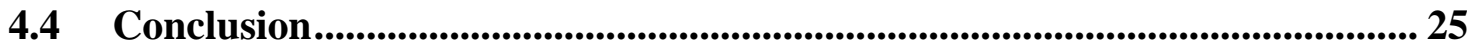

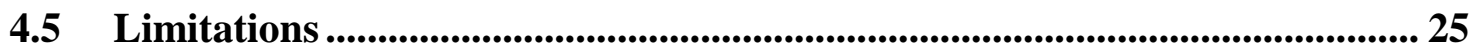

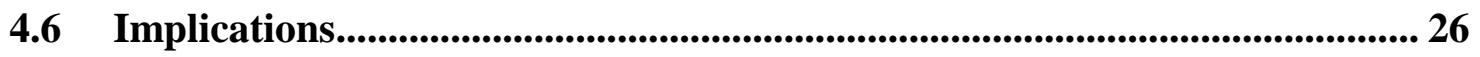

REFERENCES.............................................................................................................. 27 


\section{LIST OF TABLES}

Table 1 Children's mean production of speech in singleton and twins ..................................... 15

Table 2 Children's mean production of speech in twin dyads .............................................. 18 


\section{LIST OF FIGURES}

Figure 1 Mean amount (1A) and diversity of gestures (1B) produced per minute by singleton and twin boys and girls ....... 16

Figure 2 Mean number of different gesture types (2A) and gesture+speech combinations (2B)

produced per minute by singleton and twin boys and girls

Figure 3 Mean amount (3A) and diversity of gestures (3B) produced per minute by boy-boy, girlgirl, and girl-boy twin dyads....

Figure 4 Mean number of different gesture types (4A) and gesture+speech combinations (4B)

produced per minute by boy-boy, girl-girl, and girl-boy twin dyads 19 


\section{INTRODUCTION}

Singleton children show sex differences in early speech development, with girls producing a greater amount and variety of words and sentences at an earlier age than boys (Berglung et al, 2005; Choudhury \& Benasich, 2003). Twin children—particularly boy-boy twins—also lag behind their singleton peers in early speech development, producing fewer numbers and variety of words (Gucuyener, 2011; Hay \& O'Brien, 1983; Rice et al., 2014). However, we know relatively little about the early gestures singleton boys and singleton girls produce and whether these patterns remain similar in twin children. We know from previous work with singletons that gesture and speech form a tightly integrated system, with gesture preceding and predicting children's spoken language abilities (Iverson \& Goldin-Meadow, 2005; Özçalışkan \& GoldinMeadow, 2005a). In this study, we focus on the gestures and speech produced by three groups of fraternal twins (boy-boy, girl-girl, boy-girl), comparing them to the gestures and speech produced by boy vs. girl singletons at the early ages. We ask whether children show sex (girls vs. boys) or group (singletons vs. twins) differences in the amount, diversity and complexity of speech and gestures that they produce. We also ask whether twin dyad composition (boy-boy, girl-girl, boy-girl) influences pattern of speech and gesture production among twin children.

\subsection{Sex differences in early speech and gestures produced by singletons}

Girls outperform boys in nearly all domains of language development (Hyde \& Linn, 1988). Boys lag behind girls in their vocabulary development (Berlung et al., 2005; Eriksson et al., 2012; Fenson et al.,1994; Lange et al., 2016). More specifically, girls develop larger vocabularies, producing greater diversity of words than boys, both at the earlier $(0 ; 8-2 ; 6$; Eriksson et al., 2012; Fenson et al.,1994) and at the later ages (3;0-6;0; Lange et al., 2016), as 
assessed by parental checklist measures (e.g., the MacArthur-Bates Communicative

Development Inventories; MCDI; Fenson et al., 1994).

The sex differences become evident not only in vocabulary, but also in children's emerging syntactic abilities. Three- to five-year-old girls produce longer sentences with more diverse and complex structure than boys in one-on-one interactions with their parents (Tse et al., 2002).

These patterns remain similar in the onset of first sentences. An earlier large-scale study with 1;4 and 2;6-year-old children (2381 girls, 2310 boys), using parent checklists, showed that girls produce their first sentences earlier than boys (Eriksson et al., 2012).

Compared to speech, we know relatively little about sex differences in gesture production. The few existing studies however, mostly suggest an advantage for girls in early gesture production (Eriksson et al., 2012; Fenson et al., 1994; but see Eriksson \& Berglund, 1999 for lack of a sex difference in early gesture). These studies, relying primarily on parental checklists (e.g., MCDI) to assess the diversity of gestures 0;8-2;6-year old girls and boys produce, showed a small but consistent advantage for girls on early communicative gesture use. The female advantage in the amount of gesture production also becomes evident in the onset of gestures, with girls producing their first pointing gestures about a month earlier than boys (Butterworth \& Morisette, 1996), also assessed by parental checklists. Thus, the existing research, largely based on parental report, suggests that girls show an advantage over boys in terms of the time of onset and diversity of the gesture that they produce.

The existing research on early gesture+speech combinations that convey sentence like meanings also shows a similar female advantage. An earlier study that examined emergence of sentence like constructions in speech (e.g., "eat cookie") and in gesture+speech ("eat"+point at cookie) in 22 girls and 18 boys from ages 1;2 to $2 ; 10$ showed that girls produced not only their 
first sentences 3 months earlier than boys, but also used gesture+speech combinations to convey similar sentence-like meanings 3 months earlier than boys, suggesting a close link between the onset of sentences in speech and in gesture+speech (Özçalışkan \& Goldin-Meadow, 2010).

Overall, girls outperform boys in speech production. They use a greater amount and diversity of words and sentences than boys of comparable age, and produce their first words and sentences earlier than boys. The relatively scarce existing research on gesture- based almost exclusively on parental reports—-suggests patterns similar to speech in the production of gestures and gesture+speech combinations, with a female advantage both in the amount and time of onset of first gestures and first gesture-speech combinations.

\subsection{Sex differences in early speech and gestures produced by twins}

Most of the earlier research on twins focused on same-sex twin dyads. Several of these studies investigated the effect of child sex on language development and showed that boy-boy twins lag behind girl-girl twins in their language abilities (Davis, 1937; Day, 1932; Galsworthy et al., 2000; Garitte et al., 2002; Gücüyener et al., 2011; Hay \& O'Brien, 1983; Rice et al., 2014). Boy-boy twins are 6-to-8-months behind girl-girl twins in their expressive and receptive language skills, as assessed by parent report at age 2;6 (Hay\&O'Brien, 1983). Studies that primarily focused on vocabulary development also showed that girl-girl twins develop larger vocabularies than boy-boy twins of comparable age. This pattern was evident both at the younger ages $(2 ; 0)$ when vocabulary was assessed by parent report (Galsworthy et al., 2000; Rice et al., 2014), and at the slightly later ages $(2 ; 0-5 ; 0)$ when vocabulary was assessed using spontaneous parent-child interactions (Day, 1932). A more recent study examining same-sex twins learning Turkish showed similar results, with girl-girl twins outperforming boy-boy twins in vocabulary development (Gücüyener et al., 2011). Even though the discrepancy in vocabulary size decreases 
by age, girl-girl twins continue to have larger vocabularies than boy-boy twins at every age between ages 5;6 and 9;6 based on natural language samples (Davis, 1937). Thus, the overall patterns of vocabulary development across several studies suggest that boy-boy twins lag behind girl-girl twins.

Studies that focus on early sentences also show a female advantage among twin children. In a study involving observation of parent-child interactions between 2;0- to 5;0-year- old twins, girl-girl twins used more diverse and complex set of sentences, also with more accurate grammatical marking, than boy-boy twins of comparable age (Day, 1932) —a pattern that was also evident at the later ages (5;6 to 9;6; Davis, 1937). Similar patterns were also observed in younger age groups: 2;0-year-old girl-girl twins received higher scores on the sentence scale of MCDI, where parents were asked if their child started to combine words (i.e. doggie bite; Galsworthy et al., 2000; Rice et al., 2014).

Compared to several studies with same-sex twin dyads, there are only a few studies that examine the language development of mixed-sex twin dyads (i.e., boy-girl). Some studies suggest that girl-girl twins outperform both boy-boy and boy-girl twins in their spoken langauge abilities (Galsworthy et al., 2000), while other studies suggest that girl-girl and girl-boy twins show similar levels of performance in their spoken language abilities (Gariette et al., 2002; Gücüyener et al., 2011).

The existing studies thus far suggests an advantage in early spoken language (early words, sentences) development for girl-girl twins compared to boy-boy twins, mirroring the patterns observed in singletons: boy-boy twins lag behind girl-girl twins not only in their vocabulary, but also in the complexity, length and grammaticality of the sentences that they produce. There is, however, no research that has examined patterns of gesture production in twin dyads. 
Nonetheless, the parallels observed in patterns of speech and gesture production in singletons raise the possibility that gestures might follow a similar pattern in twins as well, with girl-girl twins outperforming boy-boy twins in the amount, diversity and complexity of the gestures that they produce.

\subsection{Differences between singletons and twins in early speech and gesture}

Twinning has a negative effect on language development. Twin children lag behind singletons in most domains of language development (Conway et al., 1980; Davis, 1937; Day, 1932; Gücüyener et al., 2011; Hay \& O’Brien, 1983; Lung et al., 2009; Mcdiarmid \& Silva, 1979; Rice et al., 2014; Rutter et al., 2003). Several studies that focused on vocabulary development showed an advantage for singletons across ages: early vocabulary assessment (ages $0 ; 6-1 ; 6)$ with parental checklists as well as later vocabulary assessment with spontaneous speech samples (age 2;6; Conway et al., 1980; ages 5;6-9;6; Davis, 1937; age 5;0; ages 2;0-5;0; Day, 1932; Gücüyener et al., 2011) or with parental checklists (age 3;0; Mcdiarmid \& Silva, 1979; ages 2;0; Rice et al., 2014; ages 1;8-3;0; Rutter et al., 2003) showed that twins lag behind singletons in the size of their vocabularies. In addition, a large longitudinal project (La Trobe Twin Study; Hay \& O'Brien, 1983), using standardized language assessments, also found that twins score lower than singletons in both expressive and receptive language at every age from age 3 to 15 . A recent study also suggests that, along with weaknesses in vocabulary development, twins also start to use their first words later than their age-matched singleton peers (Rice et al., 2014).

Twins also lag behind singletons in the diversity and complexity of the sentences that they produce (Conway et al., 1980; Davis, 1937; Day, 1932; Rutter et al., 2003). Twins produce shorter and fewer grammatical sentences than singletons at both earlier (2;6; Conway et al., 
1980) and later ages (5;6-9;6; Davis, 1937). Twins also show slower progression in early syntactic development compared to singletons, as assessed by parent reports and standardized language assessments at ages 1;8 and 3;0 (Rutter et al., 2003). The emergence of first sentences is also reported to be later for twins compared to singletons (Rice et al., 2014). Even though twin children show steady improvements in spoken language skills over time, they do not catch up with their singleton peers up until age 9;6 (Davis, 1937). In fact, by age 3;0, the disparity between the language of twin and singleton children increases (Rutter et al., 2003).

The overarching findings across many studies thus suggest that twins lag behind singletons in early language development. Even though all twin pairs (boy-boy, girl-girl, girl-boy) lag behind singletons in their language measures, boy-boy twins show the most disadvantage when compared to singletons (Conway et al., 1980; Davis, 1937; Day, 1932; Hay \& O’Brien, 1983; Mcdiarmid \& Silva, 1979; Lung et al., 2009; Rutter et al., 2003; Rice et al., 2014). In fact, a few studies that compared girl-girl twins to singletons showed that the two groups were comparable in their early spoken language skills. Both younger (2;6; Hay\&O’Brien, 1983) and older (5;0; Gucuyener et al., 2011) girl-girl twins were comparable to singleton girls in the size of their vocabularies, as well as the complexity and grammaticality of the sentences that they produced (Hay\&O’Brien, 1983).

Apart from these two studies showing strengths in vocabulary development among girlgirl twins, majority of the research thus far suggests that twin children lag behind singletons in their overall language development. On the other hand, studies exploring patterns of gesture production in singletons compared to twins remain scarce. The only existing study with older children (Carelli \& Benelli, 1987) suggests that 5- to 11-year-old twins produce more communicative gestures than their singleton peers when re-narrating a story told by an 
experimenter, but in this study, speech of twins were also found to be similar to the speech of singletons.

The explanations for the differences in language development between twins and singletons typically fall under two conceptual frameworks, highlighting either biological (Akerman et al., 1991; Briscoe et al., 1998; Lung et al., 2009; Mcdiarmid \& Silva; 1979) or environmental variables (Conway et al., 1980; Lytton, 2013; Malmstrom et al., 1986; Reznick, 1997; Rutter et al., 2003; Savic, 1979; Savic, 1980; Stafford, 1987; Thorpe et al., 2003;

Tomasello et al, 1986) as the key factors. Even though some biological factors, such as low birth weight (Akerman et al., 1991; Lung et al., 2009; Mcdiarmid \& Silva, 1979) and gestational age (Lung et al., 2009; Mcdiarmid \& Silva, 1979) have been shown to contribute to differences in the language development of twins, the majority of the studies point to environmental factors as the key contributor to differences in speech (Conway et al., 1980; Lytton, 2013; Rutter et al., 2003; Stafford, 1987; Thorpe et al., 2003; Tomasello et al, 1986). Among these factors, parent speech was found to be the most important predictor of child speech in twin dyads (Conway et al., 1980; Lytton, 2013; Rutter et al., 2003). Even though parents of twins use speech that is similar in complexity to the speech addressed to singletons, twins receive less joint attention, less childdirected speech from their parents. Twins also engage in shorter conversations with their parents (Tomasello et al, 1986). Other research also suggests that parents of twins use less interactive language and provide fewer responses to child speech compared to parents of singletons (Lytton, 2013; Stafford, 1987). Twin parents are also found to be less encouraging, involving, and responsive (Thorpe et al., 2003), showing fewer demonstrations of affection while communicating with their children (Lytton, 2013). Another environmental factor is the nature of the communication between twin siblings (Malmstrom et al., 1986; Reznick, 1997; Savic 1979; 
Savic 1980). Twin siblings have a tendency to communicate with each other more than they do with their parents, resulting in more limited language input from their parents. Twin siblings also develop their own twin language, which is different from the conventionalized language that they are learning (e.g., coin unconventional vocabulary and sentence structures; Malmstrom et al., 1986). These findings thus suggest that environmental factors might also be important in shaping the unique production patterns in twin children's language development.

\subsection{The Present Study}

Existing work provides strong evidence for sex differences in speech, with singleton girls outperforming singleton boys in early language development (Berlung et al., 2005; Eriksson et al., 2012) - a pattern that extends to twin dyads, with girl-girl twins performing better than boyboy twins (Galsworthy et al., 2000; Gücüyener et al., 2011; Rice et al., 2014). However, most of this earlier work focused on either diversity or complexity of speech, leaving amount of speech production unexamined. Compared to speech, even less is known about sex differences in gesture production of both singleton and twin children. The few existing studies, using parent checklist measures, showed a girl advantage in the diversity of gestures singleton children produced- (Eriksson et al., 2012; Fenson et al., 1994), but no research has yet explored differences in gesture use in different twin dyads.

Most of the studies that explored the effect of sex and group (twin vs. singleton) on speech were conducted with English-speaking children (Galsworthy et al., 2000; 2011; Rice et al., 2014). On the other hand, there is only one study that was conducted in Turkish (Gücüyener et al., 2011). Turkish differs from English in systematic ways from the content of children's early vocabularies (i.e., more verbs than nouns) to the ordering of elements in a sentence (flexible word order, with argument omissions; Aksu-Koç \& Ketrez, 2003; Erguvanli \& Taylan, 1984; 
Özçalışkan \& Slobin, 2003; Özyürek et al., 2008). Also, the studies that focus on the gesture production of Turkish speaking children are scarce and the existing research suggests systematic differences in the semantic content of children's gestures. For example, Turkish children start to produce their iconic gestures earlier (22.5 months) than English speaking (26 months) children (Furman et al., 2014; Özçalışkan \& Goldin-Meadow, 2011), which might be related to the greater frequency of verbs in Turkish children's early vocabularies. As such, this study will fill an important gap in the literature, helping us understand how sex and group differences affect the speech and gesture production of children learning a structurally different language, namely Turkish.

In this study, we aim to address these gaps in the literature by exploring the effect of sex and dyad composition on the amount, diversity and complexity of speech and gesture production in singletons (boys vs. girls) and twins (boy-boy, girl-girl, boy-girl). We have two questions: (1) We first ask whether children show sex (girls vs. boys) or group (singletons vs. twins) differences in the amount, diversity and complexity of speech and gestures that they produce. We predict that the previously reported sex differences in speech (Eriksson et al., 2012; Lange et al., 2016) will also be evident in our data, with girls producing a greater number, diversity and complexity of speech than age-comparable boys. We also expect group differences, with singletons producing greater number, diversity and complexity of speech and gestures than twins. We also predict that children — singleton or twin — will show sex differences in the amount diversity and complexity of the gestures that they produce, mirroring the patterns found in their speech, based on earlier parent reports of gesture production showing a female advantage (Eriksson et al., 2012; Fenson et al., 1994) (2) We next focus only on twins and ask whether dyad composition influences patterns of speech and gesture production. For speech, we predict 
that the previously reported differences (Gücüyener et al., 2011; Rice et al., 2014) will also be evident in our data, with girl-girl twins producing greater amount, diversity and complexity of speech than boy-boy and boy-girl twins. For gesture, we predict that girl-girl twins will follow the same patterns in their speech, showing greater amount, diversity and complexity in their gesture production, based on earlier work that showed a female advantage in gesturing among singleton girls (Eriksson et al., 2012; Fenson et al., 1994).

\section{METHODS}

\subsection{Participants}

The participants included three groups of fraternal twins (11 boy-boy, 9 girl-girl, 12 girlboy) and two groups of singletons (19 boys, 16 girls) — all observed as part of a larger project funded by Tubitak (362719) on morpho-syntactic development and all learning Turkish as their native language. Participants were recruited through web platforms and foundations serving twin and singleton families in the greater metropolitan Istanbul area. The children in this study were selected so that they were comparable in chronological age at the time of our observations (SingletonGIRL $=1 ; 7, \mathrm{SD}=0.47$, SingletonBOY $=1 ; 6, \mathrm{SD}=0.45 ;$ TwinBOY-BOY $=1 ; 9$, $\mathrm{SD}=0.68$, TwinGIRL-GIRL $=1 ; 10, \mathrm{SD}=0.69$, TwinGIRL-BOY $=2 ; 0, \mathrm{SD}=0.56)$ —with no age differences between all five groups of children (singleton boys, singleton girls, boy-boy twins, girl-girl twins, girl-boy twins; $\mathrm{F}(4,91)=1.99, \mathrm{p}=.10$ ) or between the three groups of twins (boyboy twins, girl-girl twins, girl-boy twins; $\mathrm{F}(2,59)=.63, \mathrm{p}=.53)$. The mean gestational age at birth was also comparable across the five groups (Msingleton girls=36.81, $\mathrm{SD}=4.18$, Msingleton boys=36.21, $\mathrm{SD}=4.80$, Mtwin girl-girl=34.89, $\mathrm{SD}=2.25$, Mtwin boy-boy=34.30, $\mathrm{SD}=2.68$, Mtwin girl-boy=34.17, $\mathrm{SD}=2.97, \mathrm{~F}(4,92)=2.18, \mathrm{p}=.08)$. Similarly, the rate of preterm birth was comparable across singleton vs. twin children and girls vs. boys: $31 \%$ (11/35) of the singleton 
and $41 \%(26 / 64)$ of the twin children were born premature; similarly, 38\% (20/53) of the boys and $37 \%(17 / 46)$ of the girls across the five groups were born preterm (range=26 to 36 weeks of gestation). We therefore included all preterm children in our sample, along with the children born at term. Majority of the parents of children had college degrees $(81 \%)$, followed by high school (18\%) and elementary school (1\%). The sample size for the study is similar to an earlier study on the gesture and speech development of children with or without autism (So et al., 2015) that detected reliable effects for a sample size of $n=14-16$ per group, $p<.05(\eta 2=0.44)$.

\subsection{Data Collection}

Children and their parents were observed in their homes, while they interacted with their primary caregivers using a set of toys (e.g., animal barn, animal puzzle) provided by the experimenter. The parents were provided with the toys and asked to play naturally with their children using any of them. The mean length of the interaction was 13 minutes, but it also varied slightly (range=5-25 minutes) based on the extent of parents' interest in playing with the toys.

\subsection{Transcription and Coding}

\subsubsection{Speech}

Video-records were transcribed and coded for morphemes in speech, following Ketrez \& Aksu-Koç (2019). All speech produced by the children were transcribed using Codes for Human Analysis Transcript (CHAT) system; and the CHAT files were analyzed using the CLAN program (MacWhinney, 2014). Sounds referring to entities, events, properties, along with onomatopoeic (e.g., "hav-hav" = woof, "çuf-çuf" = choo-choo), and conventionalized evaluative sounds ("tüh" = oopsie, "oley" =yay) were counted as words. Intelligible incomplete words (e.g., "kurabi" for "kurabiye" = cookie) were also counted as words. All speech were further 
segmented into utterances. An utterance was defined as a unit of speech separated by pauses (MacWhinney, 2014).

\subsubsection{Gesture}

All gestures that accompany each speech utterance and that were produced on their own were coded, following guidelines outlined in earlier work (Özçalışkan \& Goldin-Meadow, 2005a). A gesture was defined as a communicative hand movement that did not involve direct manipulation of objects. Each gesture was coded further for its meaning (i.e., what the gesture conveys: e.g., pointing at cat to indicate 'cat') to assess the diversity of meanings conveyed in gesture, and for its complexity (i.e., types of gestures, types of gesture+speech combinations). For types, each gesture was coded as deictic (i.e., gestures that indicate referents; e.g., point at bike), conventional (i.e., gestures that convey culturally-prescribed meanings; e.g., nod head for affirmation), or iconic (i.e., gestures that convey characteristic actions or features associated with referents; e.g., circle arms for pedaling). For types of gesture-speech combinations (i.e., gesture+speech), each gesture was coded for the informational relation it holds to the accompanying speech as either complementary gesture+speech, in which gesture conveys the same information as speech (e.g. "bike"+point at bike) or supplementary gesture+speech, in which gesture either disambiguates the information conveyed in speech (e.g. "'that it is"'+point at bike), or conveys different information from speech (e.g. "ride"+point at bike).

\subsubsection{Reliability}

We assessed the reliability for gesture coding by two trained independent coders who were blind to the hypotheses of the study. Each of them coded a randomly selected $20 \%$ of the videorecords for gesture detection, gestures meaning, and for the types of gestures and gesture+speech combinations, separately in each of the five groups; for the twin children the mean was 
calculated for the dyad. The aggrement between coders was $92 \%, \kappa=.89$ (SingletonGIRL $=90 \%$, SingletonBOY $=92 \%$, TwinBOY-BOY $=92 \%$, TwinGIRL-GIRL $=100 \%$, TwinGIRL-BOY $=$ $87 \%$ ) for the identification of the gestures, $96 \%, \kappa=.92$ (SingletonGIRL $=89 \%$, SingletonBOY $=$ 100\%, TwinBOY-BOY $=96 \%$, TwinGIRL-GIRL $=100 \%$, TwinGIRL-BOY $=96 \%$ ) for assigning gesture gloss, 98.5\%, $\kappa=.96$ (SingletonGIRL $=94 \%$, SingletonBOY $=100 \%$, TwinBOY-BOY $=100 \%$, TwinGIRL-GIRL $=100 \%$, TwinGIRL-BOY $=98.5 \%$ ) for the classification gestures into types, 96.8\%, $\kappa=.95$ (SingletonGIRL $=94 \%$, SingletonBOY $=100 \%$, TwinBOY-BOY $=91.5 \%$, TwinGIRL-GIRL $=100 \%$, TwinGIRL-BOY $=98.5 \%)$ for the classification gesture-speech combinations into types.

\subsection{Scoring}

\subsubsection{Speech}

We assessed the number of words and number of different words produced by each singleton and each twin child. We used number of words as a measure of amount, number of different types of words (e.g., "kedi"=cat vs. "kopek"=dog) as a measure of diversity, and the number of morphemes per utterance (i.e., mean length of utterance) as a measure of complexity for speech production. We treated words with the same stem but with different derivational morphemes ("write" vs. "writer") as well as words with the same stem but with different inflectional morphemes (e.g., "write" vs. "writing" vs. "writes" as three word types) as different word types.

\subsubsection{Gesture}

We assessed the number of gestures and the number of different gesture referents produced by each child. We used the number of gestures as a measure of amount, and the number of different referents conveyed in gesture (e.g., point at cat vs. point at dog) as a measure of 
diversity for gesture production. We also counted the number of each type of gesture (deictic, conventional, iconic) and gesture-speech combination (complementary, supplementary) as measures of complexity of gesture production, for each individual child. Iconic gestures and supplementary gesture-speech combinations were considered as more complex than deictic gestures and complementary gesture-speech combinations, following earlier work (Özçalışkan \& Goldin-Meadow, 2005a).

\subsection{Data Analysis}

To control for the variability in the duration of parent-child play interaction across different child-parent pairs, we used children's per minute production of speech-except for MLU where we divided the number of morphemes per utterance by the total number of spoken utterances in our analysis. Considerable within and between group differences were observed in the speech and gesture production of children; we therefore transformed all speech and gesture scores by using square root. Additionally, iconic gestures were excluded from gesture type analyses because there was very limited production of iconic gesture among all groups of children (singleton girls: 7 , singleton boys: 2, boy-boy twins: 2, girl-girl twins: 5, boy-girl twins: 3 ). We first examined sex differences in the speech and gestures produced by singletons and twins, using two-way ANOVAs with sex (boy, girl) and group (singleton, twin) as between subjects factors, separately for the amount, diversity, and complexity of speech and gesture production. For the sex and group differences analysis, we used per minute production of gesture and speech by each individual child. We next examined dyad composition differences in the speech and gestures produced by children in the three twin dyads, with a set of one-way ANOVAs - with the type of twin-dyad (boy-boy, girl-girl, boy-girl) as a between subject factor- separately for the amount, diversity, and complexity of speech and gesture production. For the dyad composition 
analysis, we used per minute production of speech and gesture per dyad (collapsed across the two children) as our unit of analysis. We used non-parametric techniques-- Kruskal Wallis (Breslow, 1970) and Friedman tests (Zimmerman \& Zumbo, 1993) where the distribution of data was not normal to confirm comparability of patterns observed with parametric statistical analysis.

\section{RESULTS}

\subsection{Do children show sex or group differences in the amount, diversity, and complexity of speech and gestures that they produce?}

Children's speech production did not show an effect of sex for either the amount $(\mathrm{F}(1,93)$ $=.04, \mathrm{p}=.85)$, diversity $(\mathrm{F}(1,93)=.06, \mathrm{p}=.80)$, or complexity $(\mathrm{F}(1,93)=.11, \mathrm{p}=.75)$ of speech. On the other hand, there was an effect of group for both the amount $(\mathrm{F}(1,93)=5.57, \mathrm{p}=$ $.02, \eta \mathrm{p} 2=.06)$ and diversity $(\mathrm{F}(1,93)=4.96, \mathrm{p}=.03, \eta \mathrm{p} 2=.05)$, but not complexity $(\mathrm{F}(1,93)=$ $1.67, \mathrm{p}=.19)$ of speech production. Singleton children produced greater number and variety of words than twin children. There was also no interaction between sex and group for either amount $(\mathrm{F}(1,93)=.25, \mathrm{p}=.62)$, diversity $(\mathrm{F}(1,93)=.59, \mathrm{p}=.45)$ or complexity $(\mathrm{F}(1,93)=1.80, \mathrm{p}=$ .18) of speech production (see Table 1).

Table 1 Children's mean production of speech in singleton and twins

$\underline{\text { Singletons }} \underline{\text { Twins }}$

$\begin{array}{lllll} & \text { Girl } & \text { Boy } & \text { Girl } & \text { Boy } \\ & \mathrm{n}=16 & \mathrm{n}=19 & \mathrm{n}=30 & \mathrm{n}=32 \\ \mathrm{M}_{\text {word token per minute }}(\mathrm{SD}) & 4.74(0.99) & 5.34(0.91) & 3.33(0.72) & 3.04(0.70) \\ \mathrm{M}_{\text {word diversity per minute }}(\mathrm{SD}) & 2.52(0.52) & 2.90(0.48) & 1.92(0.38) & 1.72(0.37) \\ \mathrm{M}_{\text {complexity }}(\mathrm{SD}) & 1.39(0.23) & 1.60(0.21) & 1.93(0.17) & 1.62(0.16)\end{array}$

Mean: Mean proportion, SD: Standard deviation 
Similar to speech, children's production of gestures did not show an effect of sex for either the amount $(F(1,93)=.02, p=.89)$ or diversity $(F(1,93)=.30, p=.58)$ of gestures (See Fig. 1A-1B). However, mirroring the pattern found in speech, there was an effect of group for both the amount $\left(F(1,93)=5.88, p=.02, \eta p^{2}=.06\right)$ and diversity $(F(1,93)=34.21, p<.001$, $\left.\eta \mathrm{p}^{2}=.27\right)$ of gesture production: singletons produced greater amount and diversity of gestures than twins. There was however no interaction between sex and group for either the amount $(F(1$, $93)=.04, p=.85)$ or the diversity $(F(1,93)=.09, \mathrm{p}=.76)$ of gestures produced

1A. GESTURE AMOUNT

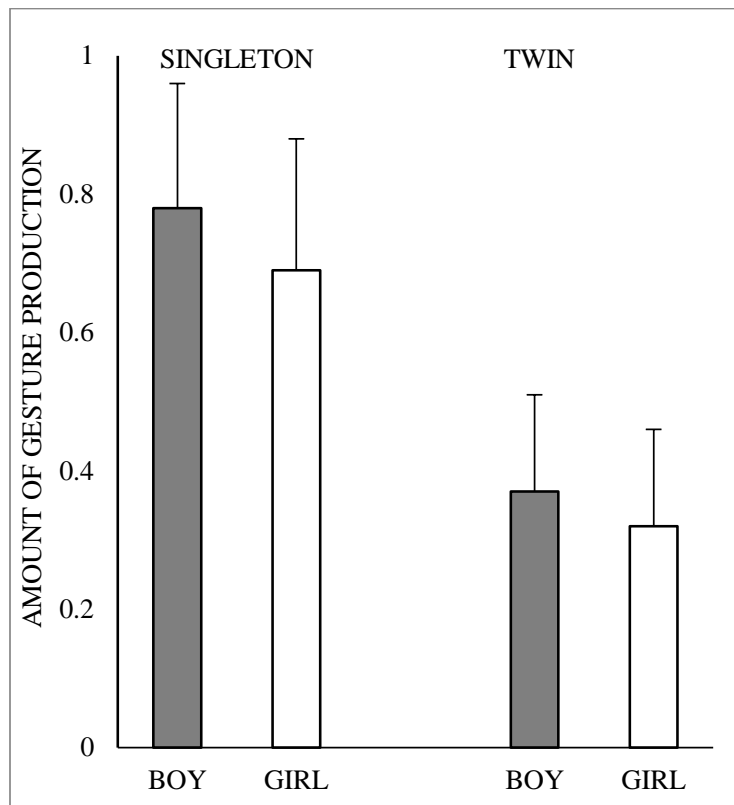

\section{B. GESTURE DIVERSITY}

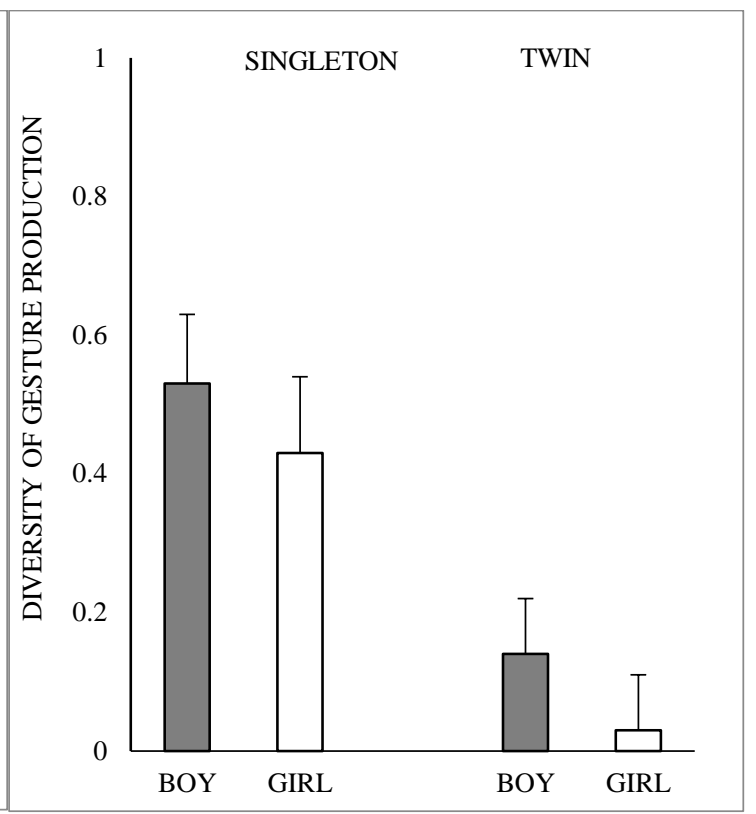

Figure 1 Mean amount (1A) and diversity of gestures (1B) produced per minute by singleton and twin boys and girls

Gesture production also showed an effect of complexity. First looking at gesture type, children's production showed an effect of gesture type $\left(F(1,93)=18.89, p=<.001, \eta p^{2}=.285\right)$ and group $\left(F(1,93)=5.50, \mathrm{p}=.02, \eta \mathrm{p}^{2}=.054\right)$, but no effect of $\operatorname{sex}(F(1,93)=.24, p=.6)$. Two -way interactions between sex and group $(F(1,93)=.28, p=.87)$, gesture type and sex $(F(1,93)$ $=.65, p=.42)$, gesture type and group $(F(1,93)=1.80, p=.18)$, or three-way interaction 
between gesture type, sex, and group $(F(1,93)=.00, p=.98)$ were also nonsignificant. Children in both groups produced greater number of deictic gestures than conventional gestures; and singletons produced more of each type of gesture than twins (see Fig. 2A). In contrast, children's production of gesture+speeeh combinations did not show an effect of combination type $(F(1,93)$ $=0.69, p=.41), \operatorname{sex}(F(1,93)=0.06, p=.80)$, or group $(F(1,93)=2.63, p=.11)$; none of the two-way interactions between sex and group $(F(1,93)=.22, p=.64)$, gesture-speech type and $\operatorname{sex}(F(1,93)=.59, p=.44)$, gesture-speech type and group $(F(1,93)=.91, p=.34)$, or threeway interaction between gesture-speech type, sex, and group $(F(1,93)=.38, p=.54)$ were significant (See Fig. 2B).

2A. GESTURE TYPE

2B. GESTURE-SPEECH TYPE

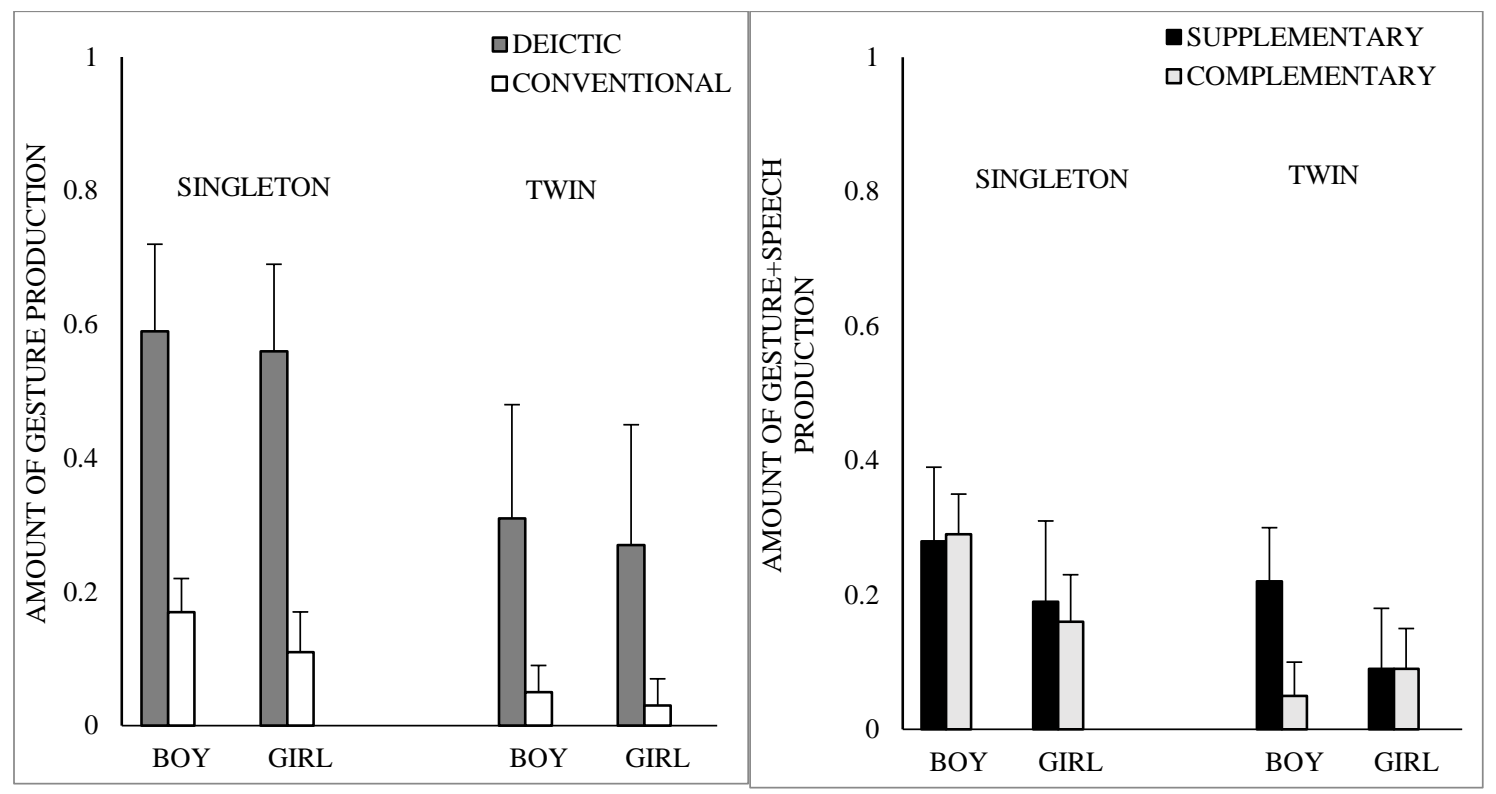

Figure 2 Mean number of different gesture types (2A) and gesture+speech combinations (2B) produced per minute by singleton and twin boys and girls 


\subsection{Do twin children show dyad composition differences in the amount, diversity, and complexity of speech and gestures that they produce?}

We next turn to three twin dyads and examine the patterns of speech and gesture production in eahc dyad. As Table 2 shows, twin dyads did not differ in the amount $(F(2,28)=$ $.58, p=.57)$, diversity $(F(2,28)=.47, p=.63)$, or complexity $(F(2,28)=.58, \mathrm{p}=.57)$ of their speech production.

Table 2 Children's mean production of speech in twin dyads

\begin{tabular}{llll}
\hline & Girl-Girl & Boy-Boy & Girl-Boy \\
& $\mathrm{n}=9$ & $\mathrm{n}=10$ & $\mathrm{n}=12$ \\
$\mathrm{M}_{\text {word token per minute }}(\mathrm{SD})$ & $6.48(6.38)$ & $4.69(5.38)$ & $7.64(8.32)$ \\
$\mathrm{M}_{\text {word diversity per minute }}(\mathrm{SD})$ & $3.93(3.87)$ & $2.76(2.89)$ & $4.11(4.44)$ \\
$\mathrm{M}_{\text {complexity }}(\mathrm{SD})$ & $3.94(2.19)$ & $2.97(1.57)$ & $3.59(2.06)$ \\
\hline
\end{tabular}

Mean: Mean proportion, SD: Standard deviation

Turning to gesture, we found that twin dyads were comparable in the amount $(F(2,28)=.03, p=.97)$ and diversity $(F(2,28)=.21, p=.81)$ of the gestures that they produced (see Fig.3A-3B). However, they differed in the complexity of their gestures. First looking at gesture type, we found no effect of group $(F(2,28)=.09, p=.91)$ and no interaction between group and gesture type $(F(2,28)=.50, p=.61)$; but we found an effect of gesture type $(F(1,28)=9.95, p=$ $.004, \eta \mathrm{p}^{2}=.262$; see Fig. 4A). Twins in each dyad produced greater number deictic gestures compared to conventional gestures. Their production of different gesture-speech combination types, on the other hand did not show an effect of group $(F(2,28)=0.13, p=.83)$, gesturespeech combination type $(F(1,28)=0.79, p=.38)$, or an interaction between group and gesturespeech combination type $(F(2,28)=0.66, p=.52$; see Fig. 4B $)$. 
3A. GESTURE AMOUNT

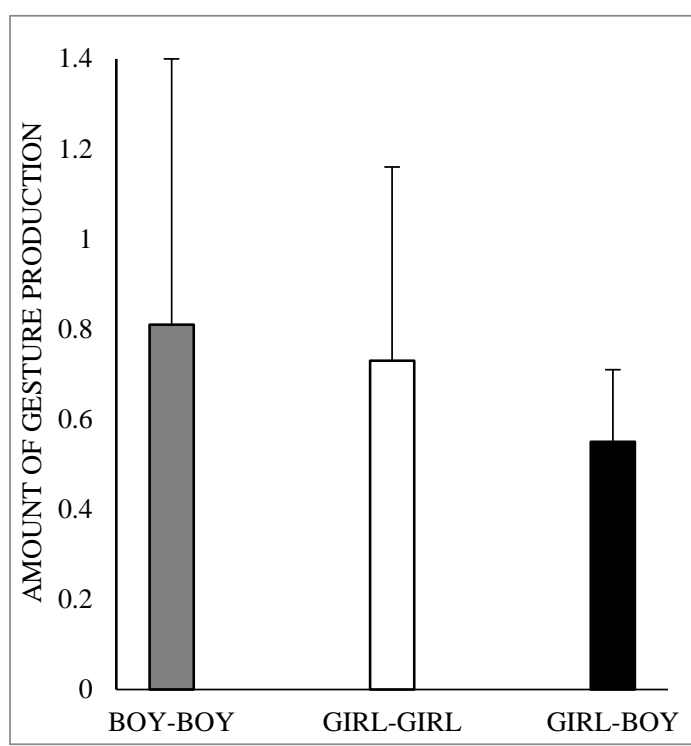

\section{B. GESTURE DIVERSITY}

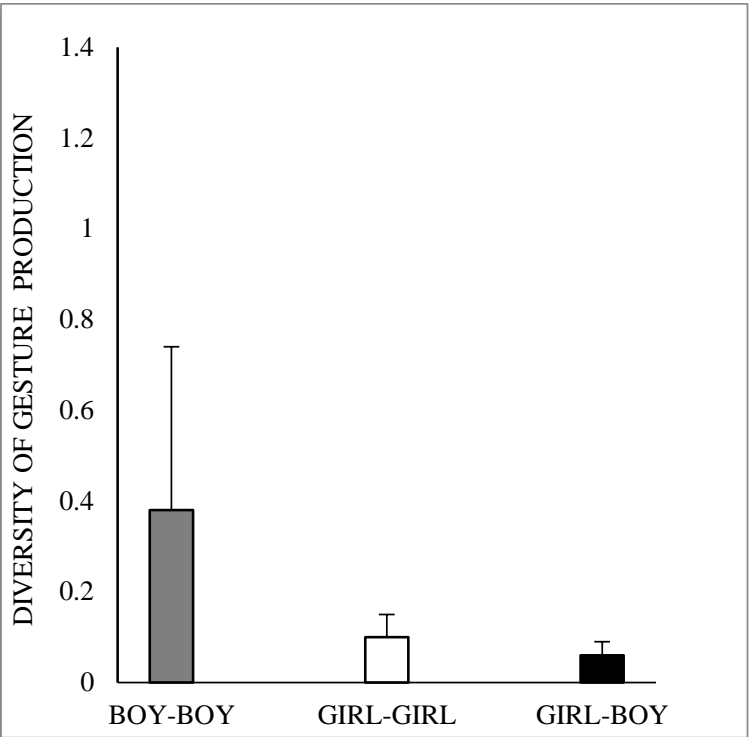

Figure 3 Mean amount (3A) and diversity of gestures (3B) produced per minute by boyboy, girl-girl, and girl-boy twin dyads

\section{A. GESTURE TYPE}

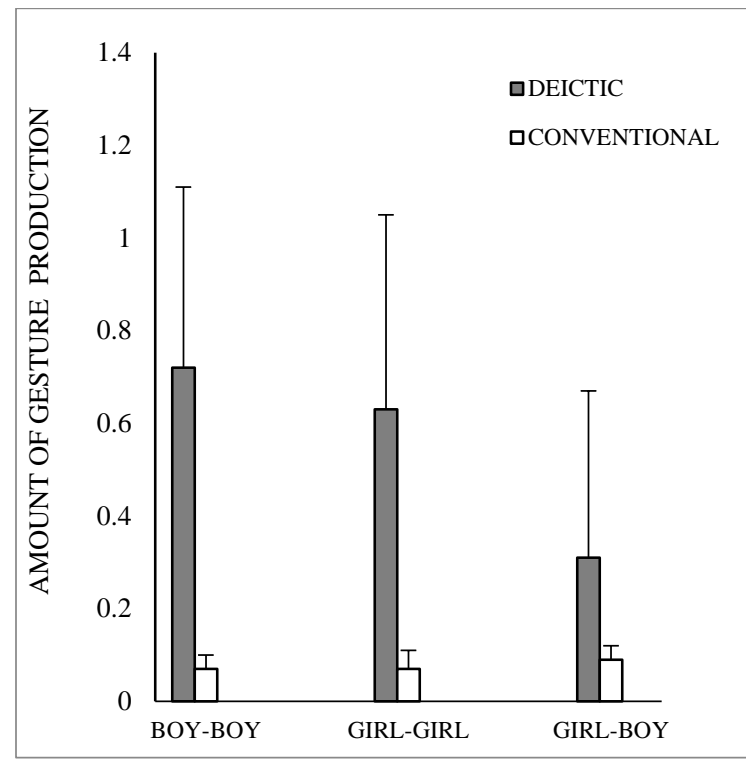

\section{B. GESTURE-SPEECH TYPE}

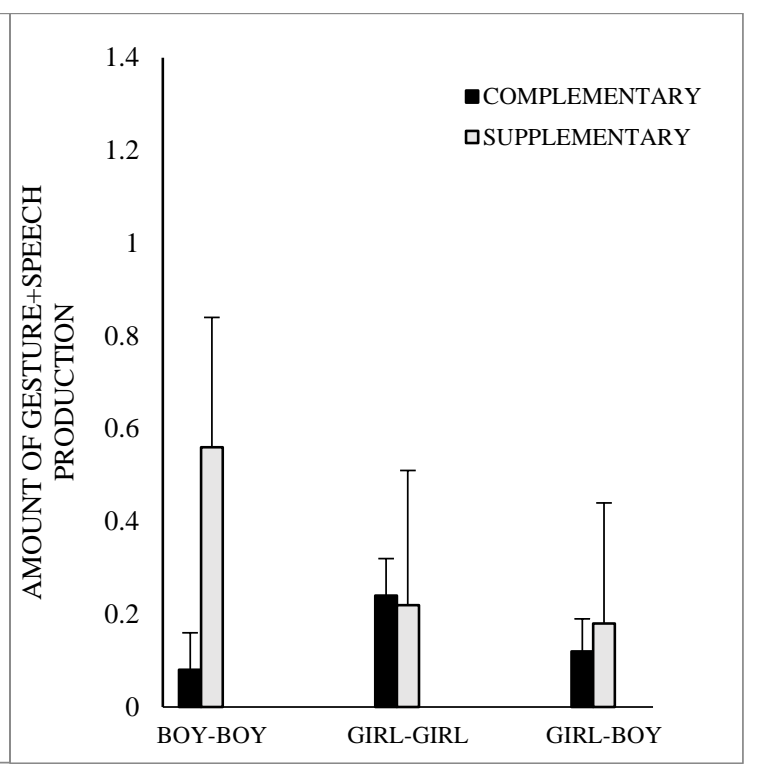

Figure 4 Mean number of different gesture types (4A) and gesture+speech combinations (4B) produced per minute by boy-boy, girl-girl, and girl-boy twin dyads 


\section{DISCUSSION}

In this study, we focused on the early gestures and speech produced by two groups of singletons (19 boys, 16 girls) and three groups of twins ( 9 girl-girl, 10 boy-boy, 12 boy-girl); we examined whether the production of gesture and speech vary by child sex and dyad composition of the twins. In contrast to previous research, our results did not show any evidence of sex differences (boy vs. girl) in the amount, diversity and complexity of the speech children produced. We, however, found group differences (singleton vs. twin) in the amount and diversity-but not complexity—of speech; twin children produced less amount and diversity of speech than singletons. Mirroring the patterns in speech, we found no sex differences in the amount, diversity and complexity of gestures, but observed a group (singleton vs. twins) difference in both the amount and diversity of gestures. Twin children produced lower amount and diversity of gestures compared to their singleton peers-a pattern that became evident in both their deictic and conventional gestures, but not in their gesture-speech combinations. The three twin dyads were comparable in their production of speech and gesture with no group differences in amount, diversity or complexity of the communications that they produced, showing no effect of dyad composition on patterns of speech and gesture production. Across groups and dyads, children preferred to use predominantly the relatively simpler deictic gestures, and were equally like to use either complementary or supplementary gesture-speech combinations.

\subsection{Group differences in gesture and speech of singletons and twins}

Supporting the previous findings, we found that twins lagged behind singletons in their speech and gesture production. We know from earlier work that gesture precedes and predicts oncoming changes in speech (Iverson \& Goldin-Meadow, 2005; Özçalışkan \& Goldin-Meadow, 
2005a; Thal \& Tobias, 1992; Thal et al, 1991). As such, the lower production of gesture production among twin children compared to singletons could be an indicator of later differences in spoken language development between the two groups. Especially, when we take into account the fact that great number of the children in our sample are at the one-word stage in their language development, their lagging behind in gesture production can be a signal of potential differences in reaching the next linguistic milestone (i.e., sentence production; Özçalışkan \& Goldin-Meadow, 2005a).

What might be the reasons for lower speech and gesture production of twins? One explanation for the gap in speech and gesture production of singleton and twin children might be the difference in parental input. Previous research found that parent speech is one of the main reasons for the slower language development among twin children (Lytton, 2013; Rutter et al., 2003; Tomasello et al, 1986). Even though twin parents produce sentences at similar levels of complexity as parents of singleton children, they nonetheless, use less interactive language (Lytton, 2013). They not only provide fewer responses to their children (Stafford, 1987), but also engage in shorter conversations with their children (Tomasello et al, 1986). To date there is no research comparing gesture production of singleton and twin parents. As is similar with the speech input, twin children might be receiving less amount and diversity of gestures directed to themselves from their parents. Additionally, joint attention (of parent and child) is crucial to recognize and understand gestures, and existing research suggests that twin children receive overall less joint attention from their parents (Lytton, 2013). Based on this, an important future direction would be to explore how twin and singleton parents use their gestures while communicating with their children. 
The communication between twin siblings can also be one of the reasons why twins lag behind singletons in their gesture production. In terms of speech, we know that having a twin sibling can negatively affect the speech development of a child (Reznick, 1997; Savic 1979; Savic 1980). Having a sibling can prevent twins from receiving the necessary language input from their parents. Twin siblings also have a tendency to develop their own language to communicate with each other (Malmstrom et al., 1986), which can have negative effects on their language development. Even though no research has yet explored the effect of communication between twin siblings on their gesture production, it is a distinct possibility that the gesture production of siblings also can negatively impact each other's gestures, mirroring the pattern reported for speech. More specifcally, the exclusive communication between twin siblings might be preventing them from receiving necessary gesture input from their parents. In this regard future research would benefit from investigation of the effect of sibling gestures on the individual child's gesture production.

\subsection{Sex differences in gesture and speech}

In our study both singleton as well as twin girls and boys were similar in their speech in contrast to previous findings showing that both singleton and twin boys lag behind girls (Eriksson et al., 2012; Rice et al., 2014). One potential reason for the lack of a difference in children's speech could be the age and language level of the children in our sample. The children in our study were relatively young and at the early stages of their language development. Most of them were communicating through words and gestures, and were not yet producing sentences. In addition to speech, we also did not find sex difference in the gesture production of boys and girls. Our finding supports previous work that showed lack of a sex difference in gesture 
production at early ages (Eriksson \& Berglund, 1999), but it also differs from two other studies that showed an advantage for girls in early gesture production (Eriksson et al., 2012; Fenson et al., 1994). It is worth noting that these earlier studies all relied on parental checklists. In contrast, our study was based on spontaneous speech sample of children, in their natural environment, which might have resulted in different patterns of gesture production.

\subsection{Differences in the complexity of the gestures children produced}

We also found that gesture production of children were affected by the different gesture types. All groups of children used the deictic gestures more than conventional and iconic gestures. One explanation for this is the young age and language level of our sample.

Developmentally, deictic gestures are the first gestures that are produced by children. Infants start to use deictic gestures (e.g. pointing, showing) to obtain the adult attention, beginning around 10 months (Bates et al., 1979; Folven \& Bonvillian, 1991). On the other hand, iconic gestures which are produced in the absence of a referent (Goodwyn \& Acredolo, 1993) are produced after a child reachess a certain level in language acquisition (i.e., 25 words) (Caselli, 1990; Nicoladis et al., 1999). Since the children in our sample were at early stages of their language development, it is not surprising that children produced greater number of deictic gestures. In terms of gesture amount, deictic gesture production was followed by conventional gestures, and then followed by the relatively scarce iconic gestures. An earlier study with Turkish children showed that Turkish children start to use iconic gestures around 22.5 months of age (Furman et al., 2014), several months earlier than children learning English. Most of the children in our study were younger than this age $\left(\right.$ Singleton $_{\mathrm{GIRL}}=1 ; 7$, Singleton $_{\mathrm{BOY}}=1 ; 6$, Twin $_{\text {BOY-BOY }}=1 ; 10$, Twin $_{\text {GIRL-GIRL }}=1 ; 10$, Twin $\left._{\text {GIRL-BOY }}=2 ; 0\right)$, possibly limiting their ability to produce iconic gestures. 
Another possible explanation for the gap in the amount of different gesture types produced by children can be the gesture production of parents. We know that parents linguistically simplify their speech and use more pronounced intonation and pitch while communicating with younger children (Fernald, 1985). They do the same with their gestures by using predominantly conceptually simpler gestures (i.e. deictic gestures), and more so than complex ones (i.e. iconic gestures). Earlier studies showed that parents mostly use deictic gestures with their young children who are between 1-3 years old. When the child gets older, parents start to use more conventional and iconic gestures which are conceptually more complex than deictic gestures (O’Neill et al. 2005; Özçalışkan \& Goldin-Meadow 2005b, 2011).

Importantly, children did not show sex or group differences in the amount of their gesture-speech combinations. They also did not differ in terms of the types of gesture-speech combinations that they used. This finding is different from previous studies showing that children at early ages use more complementary than supplementary gesture-speech combinations not only in English (Butcher, 2000; Özçalışkan \& Goldin-Meadow 2005b), but also in Turkish language (Furman et al., 2014). The children iour sample were producing reinforcing and supplementary combinations at similar rates. Once again the reason might be the particular age range under study; some of the children were at the cusp of producing their first sentences, which is a period where we expect to see an increase in supplementary gesture-speech combinations. At the same time, some other children were just beginning to produce gesture-speech combinations, which is a period where we expect to see increases in reinforcing gesture-speech combinations. Thus the relatively braod age range of children in each group might be the reason fort he lack of a significant difference in the types of gesture-speech combinations children produced. 


\subsection{Conclusion}

Our study did not sex differences in early speech and gesture production for both singleton and twin children. On the other hand, we found that twins lag behind singletons in the number and diversity of their early speech and gesture production. One of the most important contributions of this study is identifying the differences in early gesture production of twins and singletons. Until now, research has only focused on how twins and singletons differ in their speech development whereas gesture production remained relatively unexplored. However, gesture --- the precursor to speech, signals any possible future speech problems even before they are encountered. By observing the gesture production of children, we can tell the speech delays even before they appear in the speech of children. In light of these findings, gesture remains to be a very valuable tool in early identification of possible lags in language learning for twin population at risk for language problems. We know from previous work that late talkers who use more gestures to compensate for their language weaknesses catch up with their peers in one year (Thal \& Tobias, 1992). On the other hand, language problems persist in later years in children who use fewer gestures (Thal et al, 1991). Thus, gesture remains very crucial in detecting the possible future language problems earlier than they appear in speech for twin children.

\subsection{Limitations}

One of the potential limitations of this study is the relatively small sample size, particularly for the analysis involving dyad-composition differences. We addressed this issue by rerunning all comparisons with non-parametric measures and found that the patterns remain the same when using nonparametric measures. However, future research examining patterns of similarities and differences in different types of twin dyads, using larger samples, are needed to 
further understand the importance of dyad type in early gesture development. Another limitation is the variability in the amount of parent-child interaction. The duration of parent-child interaction range is between 5-25 minutes. We addressed this issue by using per minute production of gesture and speech use for each parent-child dyad. Future research that provide a more systematic and extended duration of parent-child interaction might provide a more representative sample of speech and gesture production in twin children, compared to their singleton peers.

\subsection{Implications}

In typical language development, boys tend to lag behind girls in achieving early milestones (Berlung et al., 2005; Eriksson et al., 2012); and parents tend to accept the lag as the norm for their children's spoken language development. This, in turn, could be costly in terms of child's academic success, as early language is a strong predictor of later literacy skills and academic success (Agostin \& Bain, 1997; Torppa et al., 2010). In addition, twin children, particularly boy-boy twins also tend to lag behind singleton children in their language development. If parents accept this as typical and take a wait-and-see approach instead of seeking professional help, this might have negative consequences for twin children's academic success. This study, as the first of its kind, examines effect of child sex and dyad composition in singleton and twin children on patterns of speech production and its precursor, gesture production. As such, the study has the potential to identify evidence of potential delays in children's speech at an earlier age, by observing early gestures. The patterns of gesture use, differed by group (singletons vs. twins) have important implications in devising educational strategies that target children who are at risk for delays in spoken language development. 


\section{REFERENCES}

Agostin, T. M., \& Bain, S. K. (1997). Predicting early school success with developmental and social skills screeners. Psychology in the Schools, 34(3), 219-228.

Åkerman, B. A., \& Fischbein, S. (1991). Twins: are they at risk? A longitudinal study of twins and nontwins from birth to 18 years of age. Acta geneticae medicae et gemellologiae: twin research, 40(1), 29-40.

Aksu-Koç, A., \& Ketrez, F. N. (2003). Early verbal morphology in Turkish: Emergence of. Development of verb inflection in first language acquisition: A cross-linguistic perspective, $21,27$.

Bates, E., Bretherton, I., Camaioni, L., \& Volterra, V. (1979). Cognition and communication from nine to thirteen months: Correlation findings. The emergence of symbols: Cognition and communication in infancy, 33-68.

Berglund, E. V. A., Eriksson, M., \& Westerlund, M. (2005). Communicative skills in relation to gender, birth order, childcare and socioeconomic status in 18-month-old children. Scandinavian journal of psychology, 46(6), 485-491.

Briscoe, J., Gathercole, S. E., \& Marlow, N. (1998). Short-term memory and language outcomes after extreme prematurity at birth. Journal of Speech, Language, and Hearing Research, 41(3), 654-666.

Breslow, N. (1970). A generalized Kruskal-Wallis test for comparing K samples subject to unequal patterns of censorship. Biometrika, 57(3), 579-594.

Butcher, C. (2000). Two-word speech: when hand and mouth come together. Language and gesture, 2, 235 . 
Butterworth, G., \& Morisette, P. (1996). Onset of pointing and the acquisition of language in infancy. Journal of Reproductive and Infant Psychology, 14 (3), 219-231.

Carelli, M. G., \& Benelli, B. (1987). Referential Communication Skills in Twin Children.

Caselli, M. C. (1990). Communicative gestures and first words. In From gesture to language in hearing and deaf children (pp. 56-67). Springer, Berlin, Heidelberg.

Conway, D., Lytton, H., \& Pysh, F. (1980). Twin-singleton language differences. Canadian Journal of Behavioural Science/Revue canadienne des sciences du comportement, 12(3), 264.

Davis, E. A. (1937). The development of linguistic skills in twins, singletons with siblings, and only children from age five to ten years.

Day, E. J. (1932). The development of language in twins: I. A comparison of twins and single children. Child Development, 3(3), 179-199.

Epir, S., \& Yalaz, K. (1984). Urban turkish children's performance on the Denver developmental screening test. Developmental Medicine \& Child Neurology, 26(5), 632-643.

Erguvanli, E. E., \& Taylan, E. E. (1984). The function of word order in Turkish grammar (Vol. 106). Univ of California Press.

Eriksson, M. \& Berglund, E. (1999). Swedish early communicative development. First Language, 19, 55-90.

Eriksson, M., Marschik, P. B., Tulviste, T., Almgren, M., Pérez Pereira, M., Wehberg, S., \& Gallego, C. (2012). Differences between girls and boys in emerging language skills: Evidence from 10 language communities. British Journal of Developmental Psychology, 30(2), 326-343. 
Fenson, L., Dale, P. S., Reznick, J. S., Bates, E., Thal, D. \& Pethick, S. J. (1994). Variability in early communicative development. Monographs of the Society for Research in Child Development, 59, 1-173.

Fernald, A. (1985). Four-month-old infants prefer to listen to motherese. Infant behavior and development, 8(2), 181-195.

Folven, R. J., \& Bonvillian, J. D. (1991). The transition from nonreferential to referential language in children acquiring American Sign Language. Developmental Psychology, 27(5), 806.

Furman, R. (2012). Caused motion events in Turkish: Verbal and gestural representation in adults and children (Doctoral dissertation, Radboud University Nijmegen/LOT).

Furman, R., Küntay, A. C., \& Özyürek, A. (2014). Early language-specificity of children's event encoding in speech and gesture: evidence from caused motion in Turkish. Language, Cognition and Neuroscience, 29(5), 620-634.

Galsworthy, M. J., Dionne, G., Dale, P. S., \& Plomin, R. (2000). Sex differences in early verbal and non-verbal cognitive development. Developmental Science, 3(2), 206-215.

Garber, P., \& Goldin-Meadow, S. (2002). Gesture offers insight into problem-solving in adults and children. Cognitive Science, 26(6), 817-831.

Garitte, C., Almodovar, J. P., Benjamin, E., \& Canhao, C. (2002). Speech in same-and differentsex twins 4 and 5 years old. Twin Research and Human Genetics, 5(6), 538-543.

Goldin-Meadow, S., \& Butcher, C. (2003). Pointing: Where language, culture, and cognition meet. In S. Kita, Pointing toward two word speech in young children (pp. 85-107). Hillsdale, NJ: Lawrence Erlbaum Associates, 85-107. 
Goodwyn, S. W., \& Acredolo, L. P. (1993). Symbolic gesture versus word: Is there a modality advantage for onset of symbol use? Child Development, 64(3), 688-701.

Gucuyener, K., Arhan, E., Soysal, A. S., Ergenekon, E., Turan, O., Onal, E., ... \& Atalay, Y. (2011). Language assessment of non-handicapped twins at 5 years of age. Pediatrics International, 53(6), 944-949.

Hay, D. A., \& O'Brien, P. J. (1983). The La Trobe Twin Study: A genetic approach to the structure and development of cognition in twin children. Child Development, 317-330.

Hediger, M. L., Overpeck, M. D., Ruan, W. J., \& Troendle, J. F. (2002). Birthweight and gestational age effects on motor and social development. Paediatric and perinatal epidemiology, 16(1), 33-46.

Hyde, J.S., \& Linn, M.C. (1988). Gender differences in verbal ability: a meta-analysis. Psychological Bulletin, 104 (1), 53- 69.

Iverson, J. M., Capirci, O., \& Caselli, M. C. (1994). From communication to language in two modalities. Cognitive development, 9(1), 23-43.

Ketrez, F. N. \& Aksu-Koç, A. (2019). Turkish lexicon for morphosyntactic coding. Manuscript in preparation.

Lange, B. P., Euler, H. A., \& Zaretsky, E. (2016). Sex differences in language competence of 3to 6-year-old children. Applied Psycholinguistics, 37(6), 1417-1438.

Lung, F. W., Shu, B. C., Chiang, T. L., \& Lin, S. J. (2009). Twin-singleton influence on infant development: a national birth cohort study. Child: care, health and development, 35(3), 409-418.

Lytton, H. (2013). Parent-child interaction: The socialization process observed in twin and singleton families. Springer Science \& Business Media. 
MacWhinney, B. (2014). The CHILDES project: Tools for analyzing talk, Volume II: The database. Psychology Press.

Malmstrom, P. M., \& Silva, M. N. (1986). Twin talk: Manifestations of twin status in the speech of toddlers. Journal of Child Language, 13(2), 293-304.

Mauchly, J. W. (1940). Significance test for sphericity of a normal n-variate distribution. The Annals of Mathematical Statistics, 11(2), 204-209.

Mcdiarmid, J. M., \& Silva, P. A. (1979). Three-year-old twins and singletons: a comparison of some perinatal, environmental, experiential, and developmental characteristics. Journal of Paediatrics and Child Health, 15(4), 243-247.

Nicoladis, E., Mayberry, R. I., \& Genesee, F. (1999). Gesture and early bilingual development. Developmental Psychology, 35(2), 514.

O'Neill, M., Bard, K. A., Linnell, M., \& Fluck, M. (2005). Maternal gestures with 20-month-old infants in two contexts. Developmental Science, 8(4), 352-359.

Özçalışkan, Ş., Adamson, L. B., Dimitrova, N., \& Baumann, S. (2018). Do Parents Model Gestures Differently When Children's Gestures Differ? Journal of Autism and Developmental Disorders, 48(5), 1492-1507.

Özçalışkan, Ş., \& Goldin-Meadow, S. (2005a). Gesture is at the cutting edge of early language development. Cognition, 96(3), B101-B113.

Özçalışkan, Ş., \& Goldin-Meadow, S. (2005b). Do parents lead their children by the hand? Journal of child language, 32(3), 481-505.

Özçalışkan, Ş., \& Goldin-Meadow, S. (2010). Sex differences in language first appear in gesture. Developmental Science, 13(5), 752-760. 
Özçalışkan, Ş., Goldin-Meadow, S., Stam, G., \& Ishino, M. (2011). Is there an iconic gesture spurt at 26 months. Integrating gestures: The interdisciplinary nature of gesture. Amsterdam, NL: John Benjamins.

Özçalışkan, Ş., \& Slobin, D. I. (2003). Codability effects on the expression of manner of motion in Turkish and English. In Studies in Turkish Linguistics. Istanbul: Bogaziçi.

Özyürek, A., Kita, S., Allen, S., Brown, A., Furman, R., \& Ishizuka, T. (2008). Development of cross-linguistic variation in speech and gesture: Motion events in English and Turkish. Developmental Psychology, 44(4), 1040-1054.

Reznick, J. S. (1997). Intelligence, language, nature and nurture in young twins. Intelligence, heredity and environment, 483-504.

Rice, M. L., Zubrick, S. R., Taylor, C. L., Gayán, J., \& Bontempo, D. E. (2014). Late language emergence in 24-month-old twins: Heritable and increased risk for late language emergence in twins. Journal of Speech, Language, and Hearing Research, 57(3), 917928.

Rowe, M. L., Özçalışkan, Ş., \& Goldin-Meadow, S. (2008). Learning words by hand: Gesture's role in predicting vocabulary development. First language, 28(2), 182-199.

Rutter, M., Thorpe, K., Greenwood, R., Northstone, K., \& Golding, J. (2003). Twins as a natural experiment to study the causes of mild language delay: I: Design; twin-singleton differences in language, and obstetric risks. Journal of Child Psychology and Psychiatry, 44(3), 326-341.

Savić, S. (1979). Mother-child verbal interaction: the functioning of completions in the twin situation. Journal of Child Language, 6(1), 153-158. 
Savić, S. (1980). How twins learn to talk: A study of the speech development of twins from 1 to 3. Academic Pr.

Stafford, L. (1987). Maternal input to twin and singleton children: Implications for language acquisition. Human Communication Research, 13(4), 429-462.

So, W. C., Wong, M. K. Y., Lui, M., \& Yip, V. (2015). The development of co-speech gesture and its semantic integration with speech in 6-to 12-year-old children with autism spectrum disorders. Autism, 19(8), 956-968.

Thal, D. J., \& Tobias, S. (1992). Communicative gestures in children with delayed onset of oral expressive vocabulary. Journal of Speech, Language, and Hearing Research, 35(6), 1281-1289.

Thal, D., Tobias, S., \& Morrison, D. (1991). Language and gesture in late talkers: A 1-year follow-up. Journal of Speech, Language, and Hearing Research, 34(3), 604-612

Thorpe, K., Rutter, MS., \& Greenwood, R. (2003). Twins as a natural experiment to study the causes of mild language delay: II: Family interaction risk factors. Journal of Child Psychology and Psychiatry, 44(3), 342-355.

Tomasello, M., Mannle, S., \& Kruger, A. C. (1986). Linguistic environment of 1-to 2-year-old twins. Developmental Psychology, 22(2), 169.

Torppa, M., Lyytinen, P., Erskine, J., Eklund, K., \& Lyytinen, H. (2010). Language development, literacy skills, and predictive connections to reading in Finnish children with and without familial risk for dyslexia. Journal of learning disabilities, 43(4), 308321. 
Tse, S. K., Chan, C., Li, H., \& Kwong, S. M. (2002). Sex differences in syntactic development: Evidence from Cantonese-speaking preschoolers in Hong Kong. International Journal of Behavioral Development, 26(6), 509-517.

Zimmerman, D. W., \& Zumbo, B. D. (1993). Relative power of the Wilcoxon test, the Friedman test, and repeated-measures ANOVA on ranks. The Journal of Experimental Education, 62(1), 75-86. 